\title{
The MBD4 Gene Plays an Important Role in Porcine Adipocyte Differentiation
}

\author{
Lian-Jiang Zhanga,b Ya-Nan Zhua Yan Gao Si-Yuan Liua Bo Zhai ${ }^{a}$ \\ Chang-Hong Li $i^{a}$ Hui-Yu Liu ${ }^{a}$ Jian Chen ${ }^{a}$ Bao Yuan ${ }^{a}$ Li-Sheng Daia \\ Jia-Bao Zhang ${ }^{\text {a }}$ \\ ${ }^{a}$ College of Animal Sciences, Jilin University, Changchun, ${ }^{b}$ College of Animal Science and Technology, \\ Jilin Agricultural Science and Technology College, Jilin, China
}

\section{Key Words}

Pig • MBD4 • Adipocyte differentiation • RNAi • Methylation

\begin{abstract}
Background: MBD4 (methyl-CpG binding domain protein 4) is an important G: T glycosylase that can identify T-G mismatches. It plays a role in active demethylation through base excision repair. Overexpression of MBD4 gene can cause the demethylation of numerous genes, and the remethylation of MBD4-associated genes can occur when the MBD4 gene is knocked out. To date, the functions and regulatory mechanisms of the MBD4 gene in the differentiation of porcine preadipocytes have not been clearly established. Methods: Subcutaneous fat cells from 1- to 7-day-old Junmu-1 piglets were cultured in vitro, induced to differentiate, and then identified. A real-time fluorescence-based quantitative polymerase chain reaction (PCR) analysis was conducted to detect MBD4 messenger RNA (mRNA) expression. Cells were treated with MBD4-siRNA (small interfering RNA) and induced to differentiate. Changes in the lipid droplets were observed by oil red $O$ staining. Changes in the mRNA and protein expression levels of MBD4 and the adipose differentiation-associated genes C/EBP $\alpha$ (CCAAT-enhancerbinding protein alpha), PPARY (peroxisome proliferator-activated receptor gamma), and aP2 (adipocyte protein 2) were detected. In addition, the bisulfite sequencing method was used to detect changes in methylation in the promoters of certain genes associated with adipose differentiation. Results: Levels of MBD4 mRNA and protein expression varied with time over the course of the porcine adipocyte differentiation, with the highest levels of this expression observed on day two of the differentiation process. After silencing MBD4 and inducing differentiation, the production of lipid droplets decreased, the mRNA expression levels of $\mathrm{C}$ / $\mathrm{EBP} \alpha, \mathrm{PPAR} \gamma$, and aP2 were significantly reduced, and DNA methylation modification levels were significantly elevated in the examined promoter regions. Conclusion: The silencing of the MBD4 gene can influence the DNA methylation levels of preadipocyte differentiationrelated genes and subsequently inhibit the differentiation of porcine preadipocytes.

L.-J. Zhang and Y.-N. Zhu contributed equally to this article.

Copyright $\odot 2014$ S. Karger AG, Basel

Jia-Bao Zhang and Li-Sheng Dai

College of Animal Science, Jilin University, 5333 Xi'an Road, Changchun 130062 (China) and College of Animal Science, Jilin University, Changchun 130062 (China)

E-Mail zjb515@163.com and E-Mail dls@jlu.edu.cn
\end{abstract}




\section{Introduction}

Adipocytesare produced by the differentiation of preadipocytes formed from mesodermal cells during various stages of embryonic development [1]. The formation of adipocytes is a dynamic process [2], and the differentiation of preadipocytes is regulated by hormones and growth factors [3]. In addition, studies have confirmed that changes to these hormones or growth factors affect preadipocyte differentiation [4-6]. The expression of the PPAR $\gamma$ gene, which encodes a transcription factor, is induced during adipocyte differentiation; during the course of this differentiation, the transcription factor induces lipid droplet formation and the expression of genes associated with lipid storage [7]. The C/EBP $\alpha$ (CCAAT-enhancer-binding protein alpha) and PPAR $\gamma$ genes synergistically activate genes associated with fat formation and mutually promote each other's expression [8]. Adipocyte protein 2 (aP2) is another key factor that plays an important role in regulating fat formation [9]. In the preadipocyte differentiation process, the epigenome changes as the differentiation proceeds [10]. The methylation and demethylation of genomic DNA are important aspects of epigenetics. These two processes keep balance to maintain the stability of methylation profiles [11]. Regulatory networks and transcription factors play important roles in the process of preadipocyte differentiation into mature adipocytes. Changes in the expression of relevant genes can determine the course of the adipocyte differentiation process. Notably, DNA methylation can regulate the expression of adipocyte differentiation-related genes, thereby regulating adipocyte growth and development [12]. DNA methylation and demethylation involves enzymes, and changes in the expression of these enzymes can affect the methylation levels of relevant genes. In a study of adipocyte stem cell differentiation, Zhang et al. found that interference targeting the Gadd45a (growth arrest and DNA-damage-inducible 45a) gene inhibited DNA demethylation, which occurs to a significant extent in certain genes associated with osteogenic differentiation [13]. In addition, another investigation has revealed that the upregulation of the DNA methyltransferase 1 (DNMT1) and DNA methyltransferase 3 (DNMT3) genes causes genome-wide hypermethylation [14].

The MBD4 (methyl-CpG binding domain protein 4) gene encodes an important G:T glycosylase that can identify T-G mismatches and complete DNA demethylation processes through base excision repair $[15,16]$. This protein plays roles in active demethylation, cytosine deamination at target sites, DNA damage repair [17-20], and transcriptional repression [21]. In conjunction with the TDG (thymine DNA glycosylase) gene, the MBD4 gene contributes to maintaining genetic stability, activating DNA methylation $[22,23]$, and repairing $\mathrm{mCpG}$ TpG transcripts and CpG-UpG mismatches [24-26]. In zebrafish, the overexpression of MBD4 caused the demethylation of numerous genes, whereas the knocking out of MBD4 caused the remethylation of MBD4-associated genes [27]. However, the roles of the MBD4 gene in the differentiation of preadipocytes and the impact of this gene on the expression levels of associated genes have not yet been verified [10]. Moreover, pigs provide relatively ideal animal models for the study of human lipid metabolism and adipocytes [28]. In this study, porcine preadipocytes were examined to analyze how silencing the MBD4 gene affected lipogenesis and altered the expression levels and promoter methylation levels of the C/EBP $\alpha$, PPAR $\gamma$, and aP2 genes, which encode adipocyte differentiation-related transcription factors. This approach will help to elucidate the adipogenesis process and its molecular mechanisms in porcine adipose tissue.

\section{Materials and Methods}

\section{Experimental animals}

One- to seven-day-old Junmu-1 pigs were provided by the Protospecies Pig Place of Jilin University. All experiments were permitted by Jilin University regulations governing the use of experimental animals and complied with regulations established by Chinese experimental animal ethics committees. 


\section{Porcine preadipocyte isolation, culture, and induction of differentiation}

Under sterile conditions, dorsal subcutaneous adipose tissue was collected from the pigs' necks. The tissue samples were washed three times with phosphate-buffered saline (PBS) containing 5\% double antibiotics to remove impurities. Using scissors, the adipose tissue was cut into pieces with volumes of approximately $1 \mathrm{~mm}^{3}$. The tissue pieces were then placed into a centrifuge tube. Type I collagen enzyme $(1 \mathrm{mg} / \mathrm{L})$ was added to the tube, and the tissue samples were digested in a water bath at $37^{\circ} \mathrm{C}$ for $1 \mathrm{~h}$. The resulting lysate was passed through a 200 -mesh cell sieve and then centrifuged at $1500 \mathrm{rpm} / \mathrm{min}$ for 10 $\mathrm{min}$. The precipitate was collected and then resuspended in DMEM/F12 (Gibco, Beijing, China) containing $10 \%$ calf serum. The cells were seeded into 12 -well plates at a density of $5 \times 10^{4} \mathrm{cells} / \mathrm{cm}^{2}$. The plates were placed into an incubator at $37^{\circ} \mathrm{C}$ and $5 \% \mathrm{CO}_{2}$. The culture medium was changed once every two days. When the cells had grown to cover $70-80 \%$ of the bottom of the plate, the medium was removed, and a medium containing $10 \mu \mathrm{g} / \mathrm{mL}$ insulin, $1 \mu \mathrm{mol} / \mathrm{L}$ dexamethasone, $0.5 \mathrm{mmol} / \mathrm{L}$ IBMX (3-isobutyl-1-methylxanthine), and $0.1 \mu \mathrm{mol} / \mathrm{L}$ troglitazone was added. After two days, the medium was changed to a medium containing $10 \mu \mathrm{g} / \mathrm{mL}$ insulin and $1 \mu \mathrm{mol} / \mathrm{L}$ dexamethasone. The cells were cultured in this medium, and the medium was replaced once every two days until the lipid droplets appeared.

\section{Oil red $O$ staining and measurements of $O D$ (optical density) at $500 \mathrm{~nm}$}

Cells were washed three times with PBS buffer (containing 5\% double antibiotics), fixed in a freshly prepared $4 \%$ paraformaldehyde solution at $37^{\circ} \mathrm{C}$ for $30 \mathrm{~min}$, and washed three times with PBS buffer. A filtered $60 \%$ oil red 0 solution was then added to the fixed cells, which were stained at room temperature for $30 \mathrm{~min}$. The cells were then washed three times with PBS buffer to remove excess oil red 0 and then observed and photographed under a microscope. To measure the spectrophotometric absorption values (OD values), the stained cells were dissolved for $20 \mathrm{~min}$ in $1 \mathrm{~mL}$ of $100 \%$ isopropanol solution, and the OD values of the resulting solutions were measured at $500 \mathrm{~nm}$. Three replicates of this experiment were performed.

\section{RNA extraction and complementary DNA (CDNA) synthesis}

The total RNA was extracted using TRIzol (Roche, USA), and it was then reverse transcribed into cDNA using a PrimeScript RT Reagent Kit with gDNA Eraser (Takara, Japan).

\section{Fluorescence-based quantitative analysis}

A real-time polymerase chain reaction (PCR) analysis was performed using the Mastercycler ep realplex (Eppendorf, Germany) instrument and SYBR Premix Ex Taq II (Takara, Japan). Each $20 \mu \mathrm{L}$ reaction system contained $10 \mu \mathrm{L}$ of SYBR Premix Ex TaqII $(2 \times), 2 \mu \mathrm{L}$ of cDNA, $0.5 \mu \mathrm{L}$ of the upstream primer, $0.5 \mu \mathrm{L}$ of the downstream primer, and $7 \mu \mathrm{L}$ of deionized water. The following PCR conditions were utilized: denaturation at $95^{\circ} \mathrm{C}$ for $30 \mathrm{~s}$ followed by 40 cycles of $95^{\circ} \mathrm{C}$ for $5 \mathrm{~s}$ and $60-65^{\circ} \mathrm{C}$ for $30 \mathrm{~s}$. The primer sequences are shown in Table 1 [29]. Each experiment was repeated three times.

\section{SiRNA design and transfection}

Using the complete cDNA sequence of the porcine MBD4 gene (GenBank accession no. NC_010455), appropriate small interfering RNA (siRNA) target sites were selected, and the corresponding primers were designed and synthesized. A nonsense codon sequence was used as a control. The siRNA for MBD4 was named MBD4-siRNA, and the nonsense codon sequence was referred to as the negative control (Shanghai GenePharma Co., Ltd, China). Cells were seeded in a 12-well cell-culture plate at a density of $5 \times 10^{4}$ cells per well. Opti-MEM medium was added one day before transfection to promote the cell fusion rate to exceed 70\%. MBD4-siRNA or the negative control was added to Lipofectamine 2000 (Invitrogen, USA) at the same concentration. Solutions containing Lipofectamine 2000 and MBD4-siRNA or the negative control were mixed gently and allowed to stand at room temperature for $20 \mathrm{~min}$ to form siRNA/Lipofectamine complexes. The culture medium was removed from the plate, and $900 \mu \mathrm{L}$ of the complete medium followed by $100 \mu \mathrm{L}$ of the siRNA/Lipofectamine complex were added to each well. After gently shaking to mix (with a final serum concentration of $10 \%$ ), the cells were placed into an incubator at $37^{\circ} \mathrm{C}$ and $5 \% \mathrm{CO}_{2}$. After two days, differentiation was induced. The cells were then collected to determine the mRNA expression levels, oil red 0 staining results, and DNA methylation levels of MBD4-associated genes. Each experiment was repeated three times. The sequences for MBD4-siRNA are 5'-GGAGAGGCUUGGUAAAGAATT-3' 
Table 1. Primer sequences used for the RT-PCR

\begin{tabular}{|c|c|c|c|}
\hline Gene & Accession No & $\begin{array}{c}\text { Primer sequence } 5 '-3 ' \\
(\mathrm{fw}, \text { forward; rv, reverse) }\end{array}$ & $\begin{array}{c}\text { Annealing } \\
\text { temperature }\left({ }^{\circ} \mathrm{C}\right)\end{array}$ \\
\hline MBD4 & XM_003132378.1 & $\begin{array}{l}\text { fw : TAATCTCGTCCAAGAAACAC } \\
\text { rv : GTCTGCAGTTCTTGCTACC }\end{array}$ & 61 \\
\hline GAPDH & AF017079.1 & $\begin{array}{l}\text { fw : ACCCAGAAGACTGTGGATGG } \\
\text { rv : ACGCCTGCTTCACCACCTTC }\end{array}$ & 60 \\
\hline C/EBP $\alpha$ & Y11525 & $\begin{array}{l}\text { fw : AAGTCGGTGGACAAGAACAGCAACGAGTA } \\
\text { rv : ATTGTCACTGGTCAGCTCCAGCACCTT }\end{array}$ & 62 \\
\hline PPAR $\gamma$ & AJ006756 & $\begin{array}{l}\text { fw : CCTTAAACGAAGAGTCATCTTTTAGCG } \\
\text { rv : GGCTCTTCGTGAGGTTTGTTGTACAG }\end{array}$ & 61 \\
\hline $\mathrm{aP} 2$ & AF102872 & $\begin{array}{l}\text { fw : TTTGCTACCAGGAAAGTGGCTGGCAT } \\
\text { rv : GCAGTGACACCATTCATGACACATTCC }\end{array}$ & 65 \\
\hline
\end{tabular}

Table 2. Primer sequences used for the bisulfite sequencing PCR

\begin{tabular}{|c|c|c|c|}
\hline Gene & Accession No & $\begin{array}{l}\text { Primer sequence } 5^{\prime}-3^{\prime} \\
\text { (fw, forward; rv, reverse) }\end{array}$ & $\begin{array}{c}\text { Annealing } \\
\text { temperature }\left({ }^{\circ} \mathrm{C}\right)\end{array}$ \\
\hline C/EBP $\alpha$ & XM_003127015.2 & $\begin{array}{l}\text { fw: GTTTTTAAGGGGTTGGTTTTAG } \\
\text { rv: CTCCAACACCTTCTATTAAATCTCC }\end{array}$ & 56 \\
\hline PPAR $\gamma$ & AY044238.1 & $\begin{array}{l}\text { fw: TAATTGTGAGTTTTTGTTGTGGTT } \\
\text { rv: CAAAAAATACATTACCACACTATCTC }\end{array}$ & 54 \\
\hline aP2 & FJ884069.1 & $\begin{array}{l}\text { fw: TGATAATAAGTTTGTTTTATTTTATATTGG } \\
\text { rv: CTTCCAAAATAAAAAACAACCATAAAT }\end{array}$ & 56 \\
\hline
\end{tabular}

and 5'-UUCUUUACCAAGCCUCUCCTT-3', whereas the sequences for the negative control are 5'-UUCUCCGAACGUGUCACGUTT-3' and 5'-ACGUGACACGUUCGGAGAATT-3'.

\section{Western blot analysis}

Cells were washed twice by phosphate-buffered saline (PBS) and extracted in a cell lysis buffer consisting of $20 \mathrm{mmol} / \mathrm{L}$ Tris (pH 7.9), $300 \mathrm{mmol} / \mathrm{L} \mathrm{KCl}, 0.1 \% \mathrm{NP}-40,10 \%$ glycerol, $0.1 \mathrm{mmol} / \mathrm{L}$ dithiothreitol, $0.5 \mathrm{mmol} / \mathrm{L}$ EDTA, $0.5 \mathrm{mmol} / \mathrm{L}$ EGTA, and protease inhibitor cocktail. ). The resultant cell suspension was centrifuged at $16000 \mathrm{rpm}$ for $10 \mathrm{~min}$. The protein of supernatant was quantified using the Bradford buffer (Sangon biotech, Shanghai, China). The homogenized samples (30 $\mu \mathrm{g}$ crude proteins per lane) were subjected to electrophoresis on $10 \%(\mathrm{w} / \mathrm{v})$ poly-acrylamide-sodium dodecyl sulfate (SDS) gels under standard reducing conditions with protein marked (TianGen MP204, China), then transferred to polyvinylidene difluoride membranes (Millipore, USA) at $220 \mathrm{~mA}$ for $2 \mathrm{~h}$. The blocking experiment was conducted with $5 \%(\mathrm{w} / \mathrm{v})$ BSA in blocking buffer for $2 \mathrm{~h}$ at room temperature. Immunoblotting was carried out by incubating the membranes overnight at $4{ }^{\circ} \mathrm{C}$ with MBD4 (H-300, sc-10753) rabbit polyclonal IgG (1:1000 dilution) or $\beta$-actin (C4) mouse monoclonal IgG1 (1:2000 dilution). The membranes were washed three times with $1 \%(\mathrm{v} / \mathrm{v})$ Tween-20 in PBS, then hybridized with goat anti-rabbit IgG-HRP (SC-2004, 1:2000 dilution) or goat anti-mouse IgG-HRP (1:2000 dilution) for $1 \mathrm{~h}$ at room temperature, then washed with $1 \%(\mathrm{v} / \mathrm{v})$ Tween-20 in PBS for three times. The signals were detected as chemical luminescene by Tanon 5200 (Tanon Science and Technology Co.,Ltd., China). All the above antibodies were purchased from Santa Cruz Biotechnology, Inc (USA). Optical density (OD) of the bands was determined by Image J software.

\section{Analysis of the methylation levels of the gene promoters}

The EZ DNA Methylation-Direct Kit (Zymo Research, USA) was used for the bisulfite treatment of the cells. Briefly, $1 \times 10^{5}$ cells were added to $13 \mu \mathrm{L}$ of M-Digestion buffer $(2 \times)$ and $1 \mu \mathrm{L}$ of proteinase $\mathrm{K}(10 \mathrm{mg} /$ $\mathrm{mL})$, and double distilled water $\left(\mathrm{ddH}_{2} \mathrm{O}\right)$ was added until a total volume of $26 \mu \mathrm{L}$ was reached. The mixture was incubated at $50^{\circ} \mathrm{C}$ for $20 \mathrm{~min}$, removed from incubation, and then centrifuged at $10,000 \times g$ for $5 \mathrm{~min}$. Following this centrifugation, $20 \mu \mathrm{L}$ of the supernatant was collected and added to $130 \mu \mathrm{L}$ of the conversion reagent solution. After mixing, the solution was incubated at $98^{\circ} \mathrm{C}$ for $8 \mathrm{~min}, 64^{\circ} \mathrm{C}$ for $3.5 \mathrm{~h}$, and $4^{\circ} \mathrm{C}$ for $16 \mathrm{~h}$. Each sample was then transferred to a Zymo-Spin IC column that contained $600 \mu \mathrm{L}$ of the M-Binding buffer. The column was inverted several times to mix the column contents and then centrifuged at $10,000 \times g$ for $30 \mathrm{~s}$. The filtrate was removed, M-Wash buffer was added to the column, and the column was centrifuged at $10,000 \times g$ for $30 \mathrm{~s}$. The filtrate was again removed. Subsequently, $200 \mu \mathrm{L}$ of the M-Desulfonation buffer was added to the column, which was incubated at room temperature for $20 \mathrm{~min}$ and then centrifuged at $10,000 \times g$ for $30 \mathrm{~s}$. After the column was washed twice with $200 \mu \mathrm{L}$ of M-Wash buffer per wash, $10 \mu \mathrm{L}$ of 
the M-Elution buffer was added to the column to elute the DNA. The following PCR amplification conditions were employed: $4 \mathrm{~min}$ of denaturation at $94^{\circ} \mathrm{C}$; 38 cycles at $94^{\circ} \mathrm{C}$ for $45 \mathrm{~s}, 55-60^{\circ} \mathrm{C}$ for $45 \mathrm{~s}$, and $72^{\circ} \mathrm{C}$ for 45 $\mathrm{s}$; and a final extension at $72^{\circ} \mathrm{C}$ for $10 \mathrm{~min}$. The PCR products were electrophoresed on a gel, and the target band was recovered using an AP-GX-250 gel extraction kit (Axygen, Jiangshu, China). The recovered DNA fragments were then ligated into the PMD 18-T Vector (Takara, Japan). A total of 10 clonal colonies from each sample were selected and sent for sequencing by Comate Biosciences Co., Ltd. (Changchun, China). The DNA methylation levels of the gene promoters were analyzed based on the sequencing results. The experiment was repeated three times, and the primer sequences are presented in Table 2.

\section{The statistical analysis of the experimental data}

The mRNA expressionlevels of the genes of interest were analyzed using the comparative cycle threshold (Ct) method after being corrected using levels of GAPDH (glyceraldehyde 3-phosphate dehydrogenase) gene expression as a standard. The relative expression levels were calculated using $2^{-\Delta \Delta c t}$. Between-group differences were analyzed by the chi-square test, with $P<0.05$ regarded as a significant difference and $P$ $>0.05$ regarded as an insignificant difference. The bisulfite sequencing results were analyzed using the BiQ Analyzer software.

\section{Results}

The isolation, culture, and induced differentiation of porcine preadipocytes and the mRNA expression levels of MBD4 and marker genes

Lipid droplets were not observed before the porcine preadipocytes were induced to differentiate (Fig. 1A). Lipid droplets began to appear three days after differentiation was induced (Fig. 1B). These droplets could be visualized by oil red 0 staining (Fig. 1C). The porcine preadipocytes for which no differentiation-inducing treatment was performed served as a control group, and the mRNA expression levels of the examined genes in the control group during each growth period were set to one. Relative to the corresponding mRNA expression levels of the control group cells, the mRNA expression levels of the adipose differentiationassociated genes C/EBP $\alpha$, PPAR $\gamma$, and aP2 changed over the course of the differentiation process in porcine preadipocytes that were induced to differentiate. In particular, the highest expression levels of $\mathrm{C} / \mathrm{EBP} \alpha, \mathrm{PPAR} \gamma$, and aP2 were reached at two, four, and one days after inducing differentiation, respectively (Fig. 1D). The mRNA and protein expression levels of MBD4 changed over the course of the induced differentiation of the porcine preadipocytes, with the highest MBD4 expression levels reached at two days after differentiation induction (Fig. 1E-F).

\section{The effects of MBD4-siRNA transfection}

To detect the effects of interference, we examined the porcine preadipocytes treated with siRNA; the cells were collected for the extraction of RNA at one, two, and three days after transfection. Fluorescence quantitative PCR was used to determine the mRNA expression level of MBD4, and GAPDH was used as an internal reference for calibrating the analyses. The results of this analysis revealed that compared with the control group, the treated group exhibited significantly reduced MBD4 mRNA expression levels $(P<0.01)$. At two days after transfection, the highest transfection efficiency was observed (Fig. 2A). Compared with blank and negative control groups, the expression level of the MBD4 protein in the preadipocytes was significantly reduced after the cells were transfected for $2 \mathrm{~d}(P<0.01)$ (Fig. 2B). And the mRNA expression levels of the differentiation-related transcription factors C/EBP $\alpha$, PPAR $\gamma$, and aP2 were significantly decreased in the MBD4 transfection group relative to the control group (Fig. 2C).

The effects of silencing the MBD4 gene on porcine preadipocyte differentiation

To determine the effects of MBD4 gene silencing on porcine preadipocyte differentiation, porcine preadipocytes were transfected with MBD4-siRNA. After two days, the transfected 


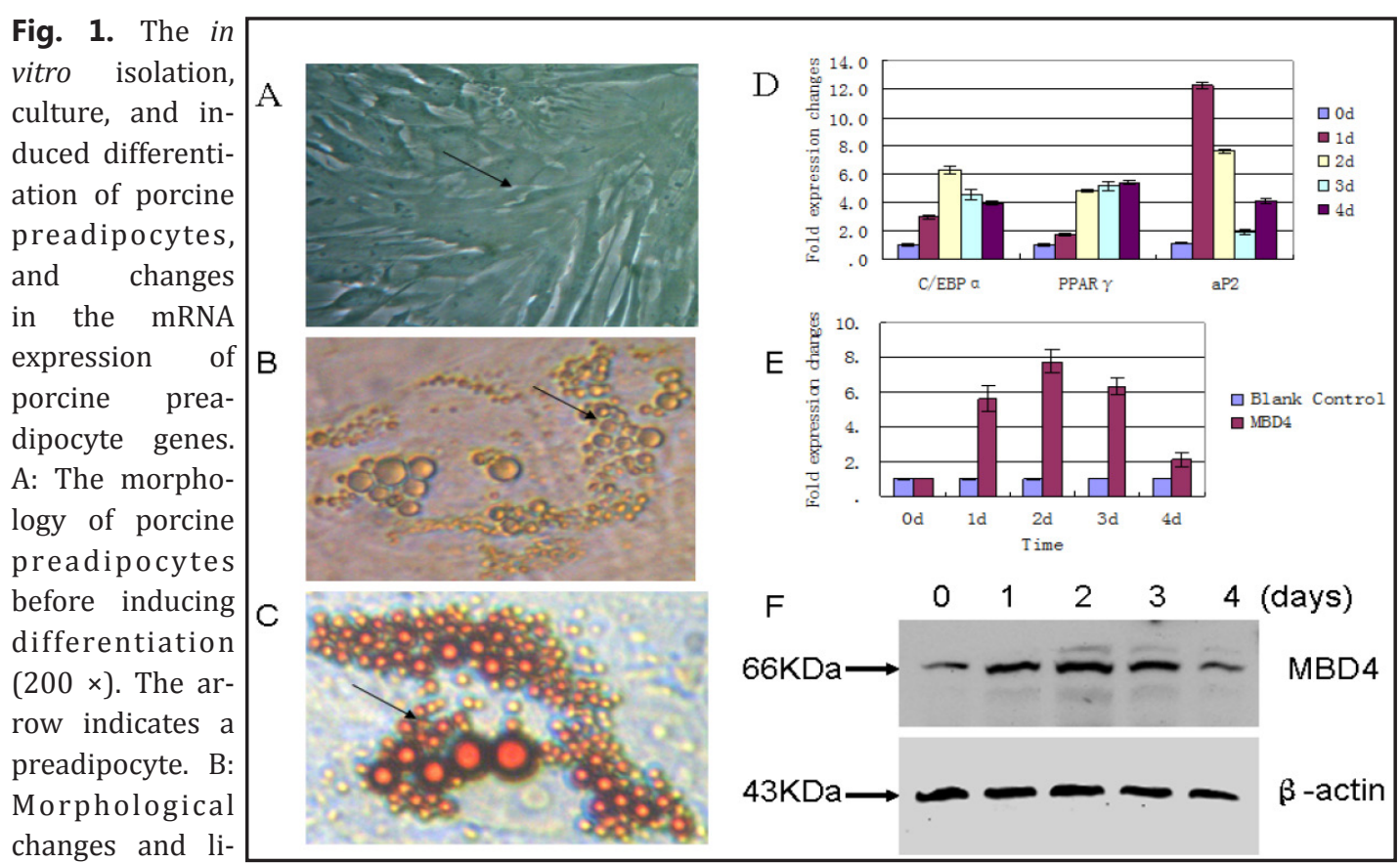
changes and lipid droplet formation in porcine preadipocytes after inducing differentiation (400 $x$ ). The arrow indicates a differentiated adipocyte. C: Morphological changes and lipid droplet formation in porcine preadipocytes after inducing differentiation (oil red 0 staining, $400 \times$ ). The arrow indicates a differentiated adipocyte. D: Changes in the mRNA expression levels of the C/EBP $\alpha, \operatorname{PPAR} \gamma$, and aP2 genes during the process of adipocyte differentiation. Uninduced preadipocytes were a control group; the GAPDH gene was used as an internal reference; the data are expressed as the means \pm std; and experiments were repeated three times. The highest levels of $\mathrm{C} / \mathrm{EBP} \alpha, \mathrm{PPAR} \gamma$, and aP2 mRNA expression were reached at two, four, and one days, respectively, after inducing differentiation. E: Changes in the mRNA expression levels of the MBD4 gene during the adipocyte differentiation process. Uninduced preadipocytes were a control group; the GAPDH gene was used as an internal reference; data are expressed as the means \pm std; and experiments were repeated three times. The highest levels of MBD4 mRNA expression occurred two days after inducing differentiation. F: Western blot analyses of change in MBD4 proteins expression level during the porcine preadipocyte differentiation process. The $\beta$-actin gene was used as an internal reference; the highest levels of MBD4 protein expression also occurred two days after inducing differentiation.

cells were induced to differentiate for four days. Then the oil red 0 staining revealed that the formation of lipid droplets in adipocytes was significantly reduced in the MBD4-siRNA transfected group relative to the blank and negative control groups (Fig. 3A-C). Compared with cells from the blank and negative control groups, cells from the MBD4-siRNA transfected group had significantly lower OD values at $500 \mathrm{~nm}$ after staining with oil red 0 (Fig. 3D). These results suggested that the silencing of the MBD4 gene inhibited the differentiation of porcine preadipocytes into adipocytes.

Elevated methylation levels of the C/EBP $\alpha, P P A R \gamma 2$, and aP2 gene promoters after the silencing of the MBD4 gene

To investigate the effects of silencing the MBD4 gene on the levels of DNA methylation modification of the genes associated with porcine preadipocyte differentiation, the bisulfite sequencing method was utilized to detect the methylation status of the relevant gene promoters after transfection for two days. The results of this examination indicated that the methylation of the C/EBP $\alpha, \operatorname{PPAR} \gamma$, and aP2 gene promoters changed after the MBD4 gene was silenced; in particular, the methylation levels of these three promoters were $1.4 \%, 70 \%$, and $54 \%$, respectively, in the control group but $2.27 \%, 92.5 \%$, and $84 \%$, respectively, in the MBD4-siRNA group (Fig. 4A-C). 
Fig. 2. The effects of silencing the MBD4 gene and the impact of this silencing on the mRNA expression levels of the $\mathrm{C} / \mathrm{EBP} \alpha, \operatorname{PPAR} \gamma$, and aP2 genes. A: The effects of silencing the MBD4 gene. The significance of the differences among the blank control, negative control, and MBD4-siRNA groups were analyzed. The MBD4-siRNA group significantly differed from the blank and negative control groups $(P<0.01, \mathrm{n}=3)$. The highest transfection efficiency was observed at two days after transfection. The differences between the blank control group and the negative control group were not significant $(P>0.05, n=3)$. The data are expressed as the means \pm std. At the same time point, results labeled with the same uppercase letter did not significantly differ $(P>0.05, \mathrm{n}=3)$, whereas results labeled with different uppercase letters significantly differed $(P<0.01, \mathrm{n}=3)$. The experiment was repeated three times. B: Western blot analyses of the MBD4 protein expression level of MBD4-siRNA group was significantly decreased compared with the blank and negative group in porcine preadipocytes after transfection with MBD4-siRNA for two days $(P<$ 0.01). a. blank control group; b. negative control group; c. MBD4-siRNA group. Optical density (OD) of the bands was determined by Image J software and normalized using internal reference gene ( $\beta$-actin). C: The effects of silencing the MBD4 gene on the mRNA expression levels of the C/EBP $\alpha$, PPAR $\gamma$, and aP2 genes. Compared with the negative control group, the MBD4-siRNA group exhibited significantly decreased mRNA expression levels of $\mathrm{C} / \mathrm{EBP} \alpha, \mathrm{PPAR} \gamma$, and aP2 after the MBD4 gene was silenced. Data are expressed as the means \pm std. The experiment was repeated three times.

Fig. 3. The effects of MBD4 gene silencing on adipocyte differentiation. A: Blank control group. B: Negative control group. C: MBD4-siRNA group. After the MBD4 gene was silenced, there were significantly fewer lipid droplets in the transfected group (C) than in the blank control group (A) or negative control group (B); D: After oil red 0 staining, OD values at $500 \mathrm{~nm}$ were significantly lower in the MBD4siRNA transfected group than in the blank control group or the negative control group. The data are expressed as the means \pm std. Results labeled with the same uppercase letters did not significantly

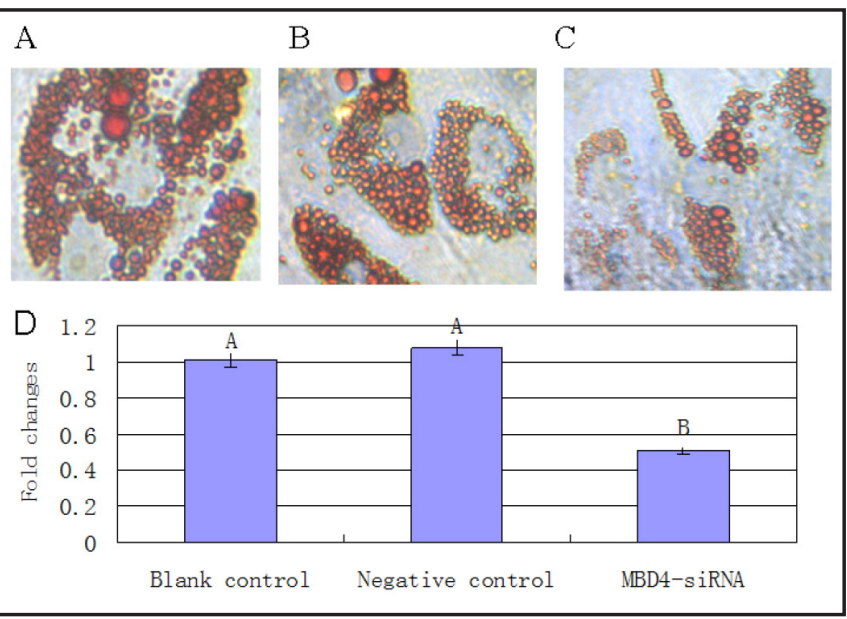
differ $(P>0.05, \mathrm{n}=3)$, and results labeled with different uppercase letters significantly differed $(P<0.01, \mathrm{n}=3)$. The experiment was repeated three times.

\section{Discussion}

The MBD4 gene plays important roles in the suppression of CpG mutations and inhibition of tumorigenesis. In a summary of prior results, the inactivation of the MBD4 gene is insufficient to trigger tumorigenesis, whereas MBD4 deletion can accelerate 
Fig. 4. The effects of MBD4 gene silencing on the DNA methylation levels of the $\mathrm{C} /$ $\mathrm{EBP} \alpha, \mathrm{PPAR} \gamma$, and aP2 genes. A: The effects of MBD4 gene silencing on the DNA methylation level of the C/EBP $\alpha$ gene. The DNA methylation level of the $\mathrm{C} / \mathrm{EBP} \alpha$ gene increased from $1.4 \%$ to $2.27 \%$. B: The effects of MBD4 gene silencing on the DNA methylation level of the PPAR $\gamma$ gene. The DNA methylation level of the PPAR $\gamma$ gene increased from $70 \%$ to $92.5 \%$. C: The effects of MBD4 gene silencing gene on the DNA methylation level of the aP2 gene. The DNA methylation level of the aP2 gene increased from $54 \%$ to $84 \%$. After PCR amplification, each PCR product was ligated into the PMD18-T vector, and 10 colonies of each product were sequenced.
A CEBP/a TSS $\longrightarrow$

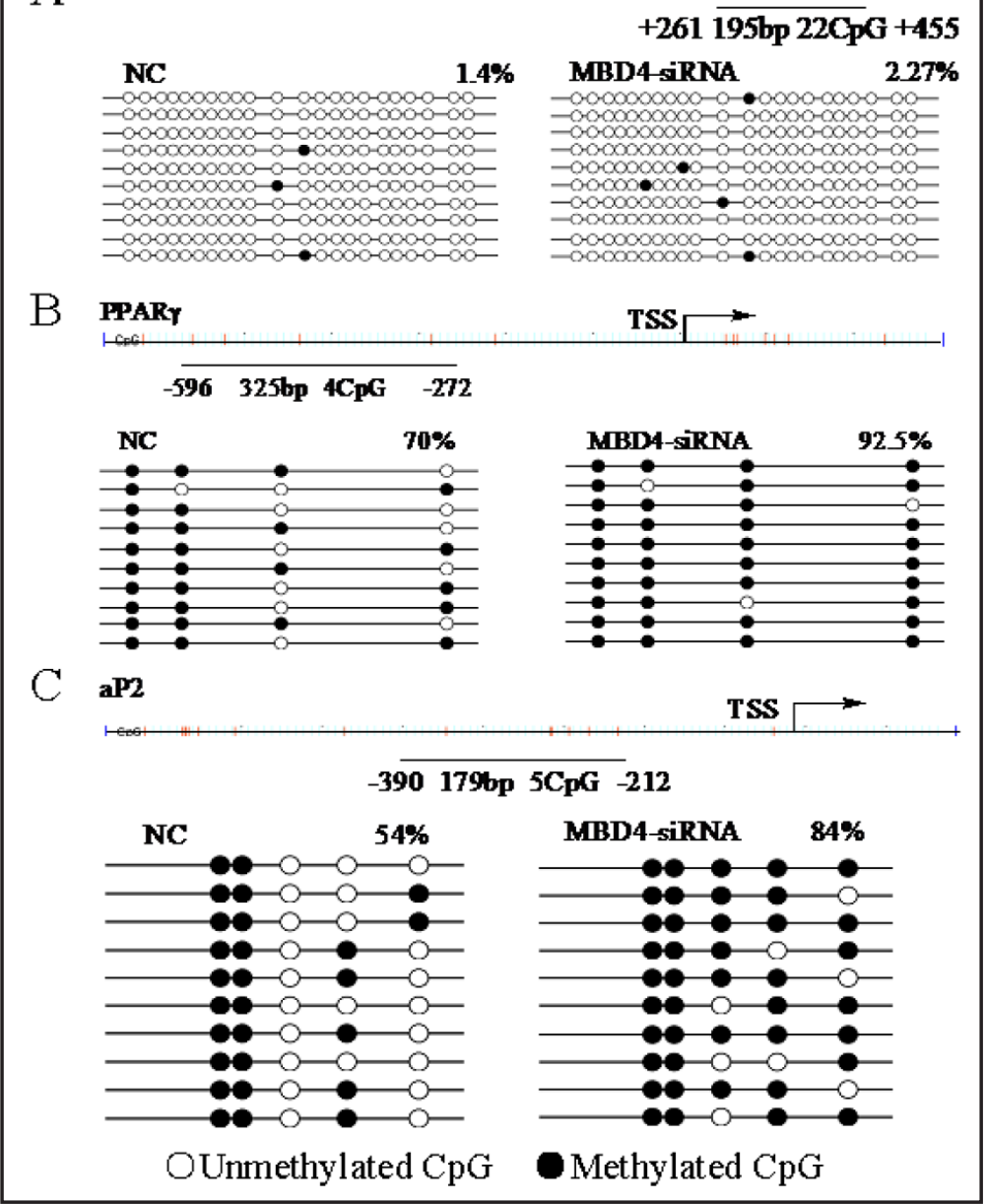

tumor formation in individuals with backgrounds predisposed to cancer because this gene performs the in vivo function of inhibiting CpG site mutations in mammalian genes [30]. In MBD4-deficient mice, $\mathrm{C} \rightarrow \mathrm{T}$ transcriptional mutations at $\mathrm{CpG}$ sites in the small intestine were increased two- to three-fold [25]. In our study, the mRNA and protein expression level were significantly decreased after the MBD4 gene was silenced (Fig. 2A-B). Moreover, examinations of changes in the number of lipid droplets and spectrophotometric values revealed that the production of lipid droplets was significantly reduced after the MBD4 gene was silenced (Fig. 3A-D), a finding that morphologically verified that the differentiation of porcine preadipocytes into mature adipocytes is inhibited when the MBD4 gene is silenced.

The differentiation of preadipocytes is associated with various alterations in the transcription of specific genes, including the regulation of differentiation-related transcription factors and changes in the expression of genes that regulate lipid metabolism [31]. These transcription factors play key roles in initiating the differentiation of preadipocytes [32]. The C/EBP $\alpha$ and PPAR $\gamma$ genes encode transcription factors that are required for the in vivo differentiation of preadipocytes into adipocytes, and these factors fulfill critical functions during the early stages of adipocyte formation and in the terminal differentiation of adipocytes $[33,34]$. PPAR $\gamma$ not only induces C/EBP $\alpha$ but also increases its own level of expression; similarly, C/EBP $\alpha$ not only induces the expression of PPAR $\gamma$ but also increases its own level of expression. This cooperation between the two factors can help to maintain high levels of C/EBP $\alpha$ and PPAR $\gamma$ expression; after appropriate levels of PPAR $\gamma$ expression have been attained, PPAR $\gamma$ stimulates the differentiation of preadipocytes [35]. Furthermore, 
$\mathrm{C} / \mathrm{EBP} \alpha$ overexpression can increase the quantities of lipid droplets produced in human omental preadipocytes [36]. Hwang et al. revealed that C/EBP $\alpha$ expression levels decreased during the late stages of 3T3-L1 differentiation and found that its expression occurred earlier than the expression of other genes that are specifically associated with adipocyte differentiation [37]. The aP2 gene is also important in adipocyte differentiation and it exhibits relatively high expression levels during the late stages of adipocyte differentiation $[38,39]$. In our study, C/EBP $\alpha$ mRNA expression levels peaked at two days after inducing preadipocyte differentiation and had begun to decline by four days after induction. PPAR $\gamma$ mRNA expression levels continued to increase four days after inducing differentiation, and aP2 mRNA expression levels were highest at one day after inducing differentiation but were also relatively high at four days after inducing differentiation (Fig. 1D). C/EBP $\alpha, \operatorname{PPAR} \gamma$, and aP2 are important adipogenic transcription factors, and adipogenesis is inhibited in transgenic animal models that lack these factors. In this study, the silencing of the MBD4 gene decreases the mRNA expression of the C/EBP $\alpha, \operatorname{PPAR} \gamma$, and aP2 genes (Fig. 2C), thereby inhibiting the formation of lipid droplets (Fig. 3A-D).

DNA methylation plays an important role in cell differentiation, and the expression of tissue-specific genes determines the direction of cell differentiation. These tissue-specific genes carry special markers, which means that these genes have particular methylation patterns. Preadipocyte differentiation-associated genes affect the differentiation of preadipocytes. Bisulfite sequencing reveals that after the silencing of the MBD4 gene, methylation is increased in the promoter regions of the CEBP $\alpha, \operatorname{PPAR} \gamma$, and aP2 genes (Fig. 4). Analyses of the causes of this phenomenon suggest that the MBD4 gene affects the formation of lipid droplets because this gene plays important roles in preadipocyte differentiation and indicates that the silencing of this gene inhibits its demethylation effects, thereby resulting in elevated methylation levels for the relevant transcription factors.

In mammals, the MBD4 gene encodes a DNA glycosylase that is involved in active DNA demethylation through the base excision repair pathway [40]. In particular, MBD4 can engage in excision and repair of mismatched bases paired with guanine $(G)$ nucleotides [41]. Methylated cytosines (C) are protected by methylation and not altered by bisulfite treatment; therefore, the PCR amplification of methylated cytosines subjected to bisulfite treatment produces cytosines (C). In contrast, non-methylated cytosines can be converted to $\mathrm{U}$ by bisulfite treatment, and the resulting U nucleotides are changed to T during PCR amplification. The sequencing results for the $\mathrm{C} / \mathrm{EBP} \alpha, \mathrm{PPAR} \gamma$, and aP2 genes reveal that cytosines (C) in the negative control group are changed to T by bisulfite conversion and PCR amplification; however, cytosines in the MBD4-SiRNA transfection group are unchanged by these treatments. These findings indicate that after the silencing of the MBD4 gene, the base repair functions of this gene are suppressed, which means that the silencing of the MBD4 gene caused the inhibition of its DNA demethylation functions. As a result, the demethylation of methylated cytosines in the promoter regions of the MBD-associated transcription factors does not occur. Because DNA demethylation plays important regulatory roles in cell proliferation, growth, and differentiation, this lack of demethylation may explain why adipogenesis is inhibited after the silencing of the MBD4 gene. In a study on the differentiation of adipose stem cells, Zhang et al. found that interference targeting the Gadd45a (growth arrest and DNA-damageinducible 45a) gene inhibited DNA demethylation, which occurs to a significant extent in certain genes associated with osteogenic differentiation [13]. We obtained similar results; in particular, this study demonstrated that in porcine adipocytes, interference with the MBD4 gene inhibited DNA demethylation and suppressed demethylation in the promoter regions of certain differentiation-related genes. Demethylation continued to occur after the silencing of the MBD4 gene; this finding suggests that although the MBD4 gene is involved in active DNA demethylation via the base excision repair pathway, demethylation involves cooperation among multiple genes and various factors. The MBD4 gene is likely only one of many factors involved in demethylation. This notion is consistent with the results of a prior study that indicated that the knockout of the MBD4 gene in early mouse embryos did not prevent the occurrence of zygotic demethylation [42]. 


\section{Acknowledgements}

This work was supported by the Youth Science Research Fund Program from Jilin Province (20140520176JH), the Program of IRT1248, the 55 ${ }^{\text {th }}$ Batch Face Funding Program from China Post-doctoral Science Fund (No.1200).

\section{References}

1 Otto TC, Lane MD: Adipose development: From stem cell to adipocyte. Crit Rev Biochem Mol Biol 2005;40:229-242.

-2 Fernyhough ME, Hausman GJ, Guan LL, Okine E, Moore SS, Dodson MV: Mature adipocytes may be a source of stem cells for tissue engineering. Biochem Biophys Res Commun 2008;368:455-457.

3 Matsumoto T, Nakajima I, Eguchi-Ogawa T, Nagamura Y, Hamasima N, Uenishi H: Changes in gene expression in a porcine preadipocyte cell line during differentiation. Anim Genet 2012;43:535-544.

4 Pang WJ, Yu TY, Bai L, Yang YJ, Yang GS: Tissue expression of porcine Fox01 and its negative regulation during primary preadipocyte differentiation. Mol Biol Rep 2009;36:165-176.

5 Hirata K, Wada K, Murata Y, Nakajima A, Yamashiro T, Kamisaki Y: Critical role of leukotriene B4 receptor signaling in mouse 3T3-L1 preadipocyte differentiation. Lipids Health Dis DOI: 10.1186/1476-511X-12122.

6 Bahar B, O'Doherty JV, O'Doherty AM, Sweeney T: Chito-oligosaccharide inhibits the demethylation of a 'CpG' island within the leptin (LEP) promoter during adipogenesis of 3T3-L1 cells. PloS One DOI: 10.1371/ journal.pone.0060011.

7 Oger F, Dubois-Chevalier J, Gheeraert C, Avner S, Durand E, Froguel P, Salbert G, Staels B, Lefebvre P, Eeckhoute J: Peroxisome proliferator-activated receptor gamma regulates genes involved in insulin/ insulin-like growth factor signaling and lipid metabolism during adipogenesis through functionally distinct enhancer classes. J Biol Chem 2014;289:708-722.

-8 Madsen MS, Siersbaek R, Boergesen M, Nielsen R, Mandrup S: Peroxisome proliferator-activated receptor gamma and C/EBPalpha synergistically activate key metabolic adipocyte genes by assisted loading. Mol Cell Biol 2014;34:939-954.

-9 Kotulak T, Drapalova J, Lips M, Lacinova Z, Kramar P, Riha H, Netuka I, Maly J, Blaha J, Lindner J, Svacina S, Mraz M, Haluzik M: Cardiac surgery increases serum concentrations of adipocyte fatty acid-binding protein and its mRNA expression in circulating monocytes but not in adipose tissue. Physiol Res 2014;63:83-94.

10 Londono Gentile T, Lu C, Lodato PM, Tse S, Olejniczak SH, Witze ES, Thompson CB, Wellen KE: DNMT1 is regulated by APT-citrate lyase and maintains methylation patterns during adipocyte differentiation. Mol Cell Biol 2013;33:3864-3878.

11 Moréra S, Grin I, Vigouroux A, Couvé S, Henriot V, Saparbaev M, Ishchenko AA: Biochemical and structural characterization of the glycosylase domain of MBD4 bound to thymine and 5-hydroxymethyuracilcontaining DNA. Nucleic Acids Res 2012;40:9917-9926.

12 Sakamoto H, Kogo Y, Ohgane J, Hattori N, Yagi S, Tanaka S, Shiota K: Sequential changes in genome-wide DNA methylation status during adipocyte differentiation. Biochem Biophys Res Commun 2008;366:360366.

13 Zhang RP, Shao JZ, Xiang LX: GADD45A protein plays an essential role in active DNA demethylation during terminal osteogenic differentiation of adipose-derived mesenchymal stem cells. J Biol Chem 2011;286:41083-41094.

14 Zhang X, Li H, Qiu Q, Qi Y, Huang D, Zhang Y: 2,4-dichlorophenol induces global DNA hypermethylation through the increase of s-adenosylmethionine and the upregulation of DNTMs mRNA in the liver of goldfish carassius auratus. Comp Biochem Physiol C Toxicol Pharmacol 2014;160:54-59.

15 Fukushige S, Kondo E, Gu Z, Suzuki H, Horii A: RET finger protein enhances MBD2-and MBD4-dependent transcriptional repression. Biochem Biophys Res Commun 2006;351:85-92.

16 Hendrich B, Hardeland U, Ng HH, Jiricny J, Bird A: The thymine glycosylase MBD4 can bind to the product of deamination at methylated CpG sites. Nature 1999;401:301-304.

17 Bogdanović 0, Veenstra GJ: DNA methylation and methyl-CpG binding proteins: Developmental requirements and function. Chromosoma 2009;118:549-565.

18 Kondo E, Gu Z, Horii A, Fukushige S: The thymine DNA glycosylase MBD4 represses transcription and is associated with methylated p16(INK4a) and hMLT1 genes. Mol Cell Biol 2005;25:4388-4396. 
19 Robertson KD: DNA methylation and human disease. Nat Rev Genet 2005;6:597-610.

20 Sansom OJ, Zabkiewicz J, Bishop SM, Guy J, Bird A, Clarke AR: MBD4 deficiency reduces the apoptotic response to DNA-damaging agents in the murine small intestine. Oncogene 2003;22:7130-7136.

21 Ballestar E, Wolffe AP: Methyl-CpG-binding proteins. Targeting specific gene repression. Eur J Biochem 2001;268:1-6.

22 Balada E, Ordi-Ros J, Serrano-Acedo S, Martinez-Lostao L, Vilardell-Tarrés M: Transcript overexpression of the MBD2 and MBD4 genes in CD4+ T cells from systemic lupus erythematosus patients. J Leukoc Biol 2007;81:1609-1616.

23 Balada E, Castro-Marrero J, Felip L, Ordi-Ros J, Vilardell-Tarrés M: Associations between the expression of epigenetically regulated genes and the expression of DNMTs and MBDs in systemic lupus erythematosus. PloS One DOI: 10.1371/journal.pone.0045897.

24 Hendrich B, Bird A: Identification and characterization of a family of mammalian methyl-CpG binding proteins. Mol Cell Biol 1998;18:6538-6547.

25 Wong E, Yang K, Kuraguchi M, Werling U, Avdievich E, Fan K, Fazzari M, Jin B, Brown AM, Lipkin M, Edelmann W: MBD4 inactivation increases $\mathrm{C} \rightarrow \mathrm{T}$ transition mutations and promotes gastrointestinal tumor formation. Proc Natl Acad Sci U S A 2002;99:14937-14942.

26 Millar CB, Guy J, Sansom OJ, Selfridge J, MacDougall E, Hendrich B, Keightley PD, Bishop SM, Clarke AR, Bird A: Enhanced CpG mutability and tumorigenesis in MBD4-deficient mice. Science 2002;297:403-405.

27 Rai K, Huggins IJ, James SR, Karpf AR, Jones DA, Cairns BR: DNA demethylation in zebrafish involves the coupling of a deaminase, a glycosylase, and GADD45. Cell 2008;135:1201-1212.

28 Spurlock ME, Gabler NK: The development of porcine models of obesity and the metabolic syndrome. J Nutr 2008;138:397-402.

-29 Nakajima I, Muroya S, Chikuni K: Growth arrest by octanoate is required for porcine preadipocyte differentiation. Biochem Biophys Res Commun 2003;309:702-708.

30 Sjolund AB, Senejani AG, Sweasy JB: MBD4 and TDG: Multifaceted DNA glycosylases with ever expanding biological roles. Mutat Res 2013;743-744:12-25.

-31 Boone C, Mourot J, Grégoire F, Remacle C: The adipose conversion process: Regulation by extracellular and intracellular factors. Reprod Nutr Dev 2000;40:325-358.

-32 Fève B: Adipogenesis: Cellular and molecular aspects. Best Pract Res Clin Endocrinol Metab 2005;19:483499.

-33 Bouraoui L, Gutiérrez J, Navarro I: Regulation of proliferation and differentiation of adipocyte precursor cells in rainbow trout (oncorhynchus mykiss). J Endocrinol 2008;198:459-469.

-34 Cao Z, Umek RM, McKnight SL: Regulated expression of three C/EBP isoforms during adipose conversion of 3T3-L1 cells. Genes Dev 1991;5:1538-1552.

-35 Tchkonia T, Giorgadze N, Pirtskhalava T, Tchoukalova Y, Karagiannides I, Forse RA, DePonte M, Stevenson M, Guo W, Han J, Waloga G, Lash TL, Jensen MD, Kirkland JL: Fat depot origin affects adipogenesis in primary cultured and cloned human preadipocytes. Am J Physiol Regul Integr Comp Physiol 2002;282:1286-1296.

-36 Jeong MY, Kim HL, Park J, An HJ, Kim SH, Kim SJ, So HS, Park R, Um JY, Hong SH: Rubi fructus (rubus coreanus) inhibits differentiation to adipocytes in 3T3-L1 cells. Evidence-based complementary and alternative medicine. Evid Based Complement Alternat Med DOI: 10.1155/2013/475386.

37 Hwang CS, Mandrup S, MacDougald OA, Geiman DE, Lane MD: Transcriptional activation of the mouse obese (OB) gene by CCAAT/enhancer binding protein alpha. Proc Natl Acad Sci U S A 1996;93:873-877.

-38 Glatz JF, Borchers T, Spener F, van der Vusse GJ: Fatty acids in cell signalling: Modulation by lipid binding proteins. Prostaglandins Leukot Essent Fatty Acids 1995;52:121-127.

-39 Tang QQ, Zhang JW, Daniel Lane M: Sequential gene promoter interactions of C/EBPbeta, C/EBPalpha, and PPARgamma during adipogenesis. Biochem Biophys Res Commun 2004;319:235-239.

40 Cortellino S, Xu J, Sannai M, Moore R, Caretti E, Cigliano A, Le Coz M, Devarajan K, Wessels A, Soprano D, Abramowitz LK, Bartolomei MS, Rambow F, Bassi MR, Bruno T, Fanciulli M, Renner C, Klein-Szanto AJ, Matsumoto Y, Kobi D, Davidson I, Alberti C, Larue L, Bellacosa A: Thymine DNA glycosylase is essential for active DNA demethylation by linked deamination-base excision repair. Cell 2011;146:67-79.

41 Hashimoto H, Zhang X, Cheng X: Excision of thymine and 5-hydroxymethyluracil by the MBD4 DNA glycosylase domain: Structural basis and implications for active DNA demethylation. Nucleic Acids Res 2012;40:8276-8284.

42 Santos F, Dean W: Epigenetic reprogramming during early development in mammals. Reproduction 2004;127:643-651. 